Pak. j. sci. ind. res. Ser. A: phys. sci. 2019 62A(3) 167-173

\title{
Characteristics of Thermal Neutron Flux Distribution in a Phantom Irradiated by Epithermal Neutron Beam from Double Layer Beam Shaping Assembly (DBSA)
}

\author{
Bilalodin $^{\text {ab**, Gede Bayu Suparta }}{ }^{\mathrm{a}}$, Arief Hermanto ${ }^{\mathrm{a}}$, Dwi Satya Palupi ${ }^{\mathrm{a}}$, \\ Yohannes Sardjono ${ }^{c}$ and Rasito ${ }^{\mathrm{d}}$ \\ ${ }^{a}$ Department of Physics, Faculty of Mathematic and Natural Science, Gajah Mada University, Indonesia \\ ${ }^{b}$ Department of Physics, Faculty of Mathematics and Natural Sciences, Jenderal Soedirman University, Indonesia \\ ${ }^{\mathrm{c}}$ Center for Accelerator Science and Technology, National Nuclear Energy Agency, Indonesia \\ ${ }^{\mathrm{d}}$ Center for Science and Applied Nuclear Technology, Bandung, Indonesia
}

(received September 12, 2018; revised February 8, 2019; accepted February 12, 2019)

\begin{abstract}
A simulation study on the Double-layer Beam Shaping Assembly (DBSA) system has been carried out. This study used fast neutron beam resulting from reactions of $30 \mathrm{MeV}$ protons with beryllium target. The MCNPX code was utilized to design the DBSA and the phantom as well as to calculate neutron flux on the phantom. The distribution of epithermal neutron flux and gamma in the DBSA and phantom were computed using the PHITS code. The spectrum of radiation beams generated by the DBSA shows the characteristics that the typical epithermal neutron flux of $1.0 \times 10^{9} \mathrm{n} /\left(\mathrm{cm}^{2} . \mathrm{s}\right)$, the ratio of epithermal to the thermal and fast neutron flux of 344 and 85 , respectively and the ratio of gamma dose to the epithermal neutron flux of $1.82 \times 10^{-13} \mathrm{~Gy} . \mathrm{cm}^{2}$. The test of epithermal neutron beams irradiation on the water phantom shows that epithermal neutrons are thermalized and penetrate the phantom up to $12 \mathrm{~cm}$ in depth. The maximum value of neutron flux is $1.1 \times 10^{9} \mathrm{n} /\left(\mathrm{cm}^{2} . \mathrm{s}\right)$ at a depth of $2 \mathrm{~cm}$ in phantom.
\end{abstract}

Keywords: double-layers BSA, MCNPX, PHITS, neutron flux, phantom

\section{Introduction}

The Boron Neutron Capture Therapy (BNCT) is a promising therapeutic method for cancer treatment owing to its capability of killing cancer cells selectively with the use of ${ }^{10} \mathrm{~B}$ compounds in the cell, irradiated by neutrons. Interactions of the neutron with ${ }^{10} \mathrm{~B}$ nucleus produce $\alpha$-particle and ${ }^{7} \mathrm{Li}$ nucleus through ${ }^{10} \mathrm{~B}(\mathrm{n}, \alpha){ }^{7} \mathrm{Li}$ reaction. It is the energy of $\alpha$ particle that is utilized to destroy cancer cells in body tissues. The range of $\alpha$ particles is short, within the size of a cell, allowing radiation effect to be focused entirely on the cancer cell and suppressing negative effects on healthy cells (Sauerwein et al., 2012). Therapies for shallow cancer are carried out with thermal neutrons while for deeper cancer with epithermal neutrons (Tanaka et al., 2011).

A neutron source currently being developed is the accelerator. An accelerator is a more feasible neutron source because of its possibility to be built close to a hospital (Kreiner et al., 2016). Cyclotron type accelerators are widely developed in various countries such as Japan, specifically the KURI Institute, which

*Author for correspondence;

E-mail: bilalodin.unsoed@gmail.com develops the C-BENS and Korea, which develops a BNCT based accelerator (AB-BNCT) (Lai and Sheu, 2017). Both types of cyclotrons use protons with 30 $\mathrm{MeV}$ of energy. One part of the cyclotron that is still in development is Beam Shaping Assembly (BSA). The BSA is a system that transforms fast neutrons into epithermal neutrons while also suppresses ensuing contaminants (Avagyan et al., 2017; Monshizadeh et al., 2015).

BSA designs used in neutron sources typically consist of a moderator, filter, reflector, and collimator as their main components (Kasesaz et al., 2014). Each of the components is commonly designed with single layer configuration, i.e., they only use one type of material. The disadvantage of the single layer configuration is that every component does not work efficiently, causing moderated fast neutrons not being transformed into epithermal neutrons with such quality and intensity that agree with the requirements of BNCT therapies. To overcome this weakness, double layer, even multilayer, configurations may be developed.

The double-layer configuration BSA or DBSA is introduced. It is expected to produce neutron beams with 
better intensity and quality from the evidence that combining two suitable materials yields better quality. Using two-layered moderators combination, Dao-wen et al. (2012) were able to improve moderation up to $19.3 \%$. Adib et al. (2016) combined two or more filter materials and succeeded to produce epithermal neutron beams within a range of 1.5 to $10 \mathrm{keV}$. Better results were also obtained when two reflectors were combined. A combination of reflector materials such as tungsten (W) and molybdenum (Mo) can multiply neutron reflection to five times as compared to when only tungsten is used (Asnal et al., 2015, Kasesaz et al., 2013).

In order to find the characteristics of BSA that consist of components made of two different materials, quality tests are required on the beams generated by the BSA (Monshizadeh et al., 2015; Kasesaz et al., 2013; Tanaka et al., 2011). In principle, there are two ways to know the quality of beams for BNCT, (a) that are by assessing their quality in the air and (b) in a water phantom. Assessment of radiation beams in the air is an assessment that complies the IAEA-TECDOC-1223 (2001). As for the assessment in the water phantom, it is emphasized on the ability of radiation beams to penetrate the phantom and the dose of neutron sustained by a tumor (Ghal-Eh et al., 2017). Water phantom is typically chosen as a testing material because $70 \%$ of a human body consists of water (Tsukamoto et al., 2011).

This article reports characteristics of radiation beams produced by DBSA and their penetration quality in the water phantom. We plan to design the DBSA combining two cheaper materials that are available in the market while maintaining good moderation, reflection, and filtering quality. If this new design of the DBSA proves successful, then the design would be implemented to the BNCT that is currently developed in Indonesia.

\section{Materials and Methods}

In this simulation study, the neutron source is from the interaction of proton $(30 \mathrm{MeV}, \mathrm{I}=1 \mathrm{~mA})$ with ${ }^{9} \mathrm{Be}$ target through ${ }^{9} \mathrm{Be}(\mathrm{p}, \mathrm{n}){ }^{9} \mathrm{~B}$ reactions (Hashimoto et al., 2014). The neutron beams are assumed to be isotropic and monoenergetic when they are radiated from the target. It is also assumed that the neutrons radiated from the target are fast neutrons, with energy of $28 \mathrm{MeV}$ and neutron yields $\leq 10^{14} \mathrm{n} / \mathrm{s}$ (Tanaka et al., 2011). Utilizing $30 \mathrm{MeV}$ protons is more advantageous on account of its ability to produce higher neutron flux than lowenergy neutron sources. To lower the energy of fast neutrons, turning them into epithermal neutrons, a
Double-layer Beam Shaping Assembly (DBSA) is used. The configuration of the DBSA is shown in Fig. 1.

Materials for DBSA components are selected regarding their corresponding functions and considering their cross-section and availability in the market. The materials used as the moderator in the design of BSA are aluminum (Al) and fluorine (F). The primary reason for the selection of $\mathrm{Al}$ and $\mathrm{F}$ is their high scattering cross-section. Aluminum has a high cross-section at energies above $10 \mathrm{keV}$ and $25 \mathrm{keV}$ in fluorine (Zaidi et al., 2017; Turkmen et al., 2017).

The materials for reflector are $\mathrm{Pb}$ and $\mathrm{FeC}$. They have high density and ability to scatter fast neutron extremely well (Sato et al., 2013). C (graphite) is also used as a reflector for its low cost. Apart from being cheap it also has high scattering cross-section and low absorption, particularly at energies above $1 \mathrm{MeV}$ (Turkmen et al., 2017).

The collimator component under considerations is made of $\mathrm{Ni}$ and borated polyethylene materials. $\mathrm{Ni}$ is considered to be a stable element when it interacts with neutrons. Some of its isotopes have a short half-life and thus safe to be used as a collimator.

For fast neutron filter, Fe materials are used. The effectiveness of $\mathrm{Fe}$ as a high energy neutron filter owes to the ability of $\mathrm{Fe}$ to inelastically scatter high energy neutrons passing through $\mathrm{Fe}$. Fe materials are deemed superior in filtering fast neutrons. The ability of Fe to filter fast neutrons derives from its resonant crosssection which is above $10 \mathrm{keV}$ (Ivakin et al., 2011). Thermal neutrons are filtered using a material with high

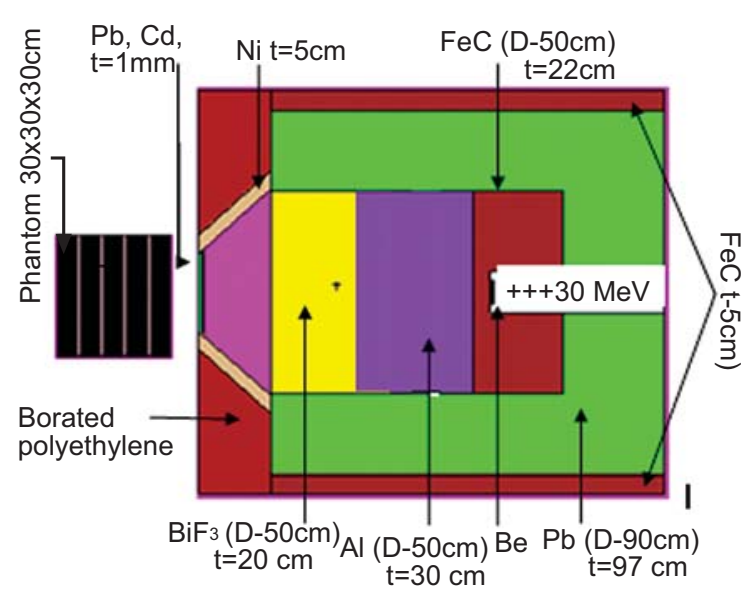

Fig. 1. Model of DBSA and water phantom. 
atomic number. Among atoms with high thermal neutrons absorption cross-section is $\mathrm{Cd}$ which is frequently used as a thermal neutron filter. A crosssection of 20.600 barn is reasonably effective to absorb thermal neutrons (Osawa et al., 2017; Asnal et al., 2015).

The material for shielding is $\mathrm{Pb}$. It has a relatively constant attenuation coefficient, i.e., $0.05 \mathrm{~cm}^{2} / \mathrm{g}$ to able to absorb gamma rays with energies of 1-10 MeV (Turkmen et al., 2017). Pb materials are better still as gamma shielding compared to $\mathrm{Bi}$. That is because during its interaction with neutrons, Bi produces a toxit and transforms into ${ }^{210} \mathrm{P}^{0}$.

The BSA model being developed as high energy neutron beam processor uses a model of double layer having moderator, reflector, collimator and filter as its primary component, and neutron beam channel that is cylindrical and conical in shape. The model of proton channel in the BSA is in form of a cylinder coated by $\mathrm{Pb}$ material. The function of $\mathrm{Pb}$ coating as proton reflector is to keep proton from spreading and maintain its focus into the target (Khorshidi, 2017; Hasimoto et al., 2015; Tanaka et al., 2011)

Epithermal neutrons leaving the DBSA are subsequently imposed on water phantom, shaped as $30 \mathrm{~cm} \times 30 \mathrm{~cm}$ $\times 30 \mathrm{~cm}$ box, which is placed $1 \mathrm{~cm}$ at the front of the DBSA. In order to determine the change in epithermal neutron flux into thermal neutrons in phantom, a $1 \times 1$ $\times 1 \mathrm{~cm}$ detector cell was placed in the phantom. The distance between the detectors and each other is $1 \mathrm{~cm}$. The composition of the water phantom is $11.2 \%$ of $\mathrm{H}$ atoms and $88.8 \%$ of $\mathrm{O}$ atoms, with the density of 1000 $\mathrm{kg} / \mathrm{cm}$ (Kreiner et al., 2016; Raaijmakers et al., 2000).

The software used in designing and analyzing particle transports in the DBSA is the Monte Carlo method. Two codes that are used are MCNP and PHITS. Both softwares are widely used in the field of nuclear reactor physics, accelerator design, medical physics (Solovyev et al., 2015; Sato et al., 2013).

In designing the DBSA, the Monte Carlo N particle $\mathrm{X}$ (MCNPX) 2.7 code is used (Pelowitz, 2005). The code is run with particle history of $10^{6}$ and multiplication factor of $6.25 \times 10^{15} \mathrm{n} / \mathrm{s}$, in $\mathrm{n} \mathrm{p} \mathrm{h} \mathrm{Mode} \mathrm{and} \mathrm{tally} \mathrm{F5}$ for calculations of important parameters, i.e. thermal neutron beams, epithermal neutron beams, fast neutrons, and gamma dose. Tally DE and DF are used to change fluxes into doses. The corresponding microscopic cross section data is used for simulation by using the ENDF/BVII and Visual Editor to visualize the geometry of the
MCNPX input. NPS is set to million for each run to ensure the tally results to meet requirement of $10 \%$ uncertainly in statistics.

The distributions of neutron and gamma flux in the DBSA and phantom are computed using the Particle and Heavy Ion Transport System (PHITS) code. (Sato et al., 2013). PHITS is also used to determine the spectrum of outgoing neutron-flux on the aperture surface. The track length tally is used in the PHITS calculation. To draw the particle track and visualization geometry of DBSA, the ANGEL software is used. The transport is based on the cross-section data library JENDL-4.0 for neutron and photon, and intra-nuclear cascade (INCL4.6) for proton.

\section{Results and Discussion}

Characteristics of epithermal neutron beams from

DBSA. Figure 1 shows DBSA as a system processing fast neutrons into epithermal neutrons and suppressing contaminants. DBSA has four main components, those are moderator, reflector, collimator, and filter. Each of the components is formed by a combination of two materials. The moderator is formed of $\mathrm{Al}$ and $\mathrm{BiF}_{3}$ materials, particularly by combining materials with small and large Z. Such combinations are expected to moderate high neutron energy effectively and gradually (Mozhayev et al., 2016). The reflector is formed of a combination of $\mathrm{Pb}$ and $\mathrm{FeC}$. $\mathrm{Pb}$ functions reflect neutron beams back into the moderator. $\mathrm{Pb}$ materials possess good reflectivity property, owing to its large scattering cross section and low absorption cross section fast neutron (Takata et al., 2010). The collimator is formed of a combination of $\mathrm{Ni}$ and borated polyethylene, and the filter is formed of a combination of $\mathrm{FeC}$ and $\mathrm{Cd}$ materials. Fe is used as the filter for fast neutrons and $\mathrm{Cd}$ as a thermal neutron filter. The use of two materials on every component of DBSA is intended to enhance the contribution of each material.

Figure 2 shows the distribution of epithermal neutron in the DBSA. Epithermal neutrons resulted from the moderation of fast neutrons produced from interactions of $30 \mathrm{MeV}$ protons with beryllium target (Hashimoto et al., 2015). Highest epithermal neutron fluxes are distributed around $\mathrm{FeC}$ filter and $\mathrm{AL}$ and $\mathrm{BiF}_{3}$ moderator. Epithermal neutron flux in the vicinity of moderator and filter reaches $10^{11} \mathrm{n} /\left(\mathrm{cm}^{2} . \mathrm{s}\right)$. The ability of the moderator in moderating fast neutrons into epithermal neutrons is accounted for by fluorine $(\mathrm{F})$ in the $\mathrm{BiF}_{3}$ material and aluminum (Al) as constituting components 


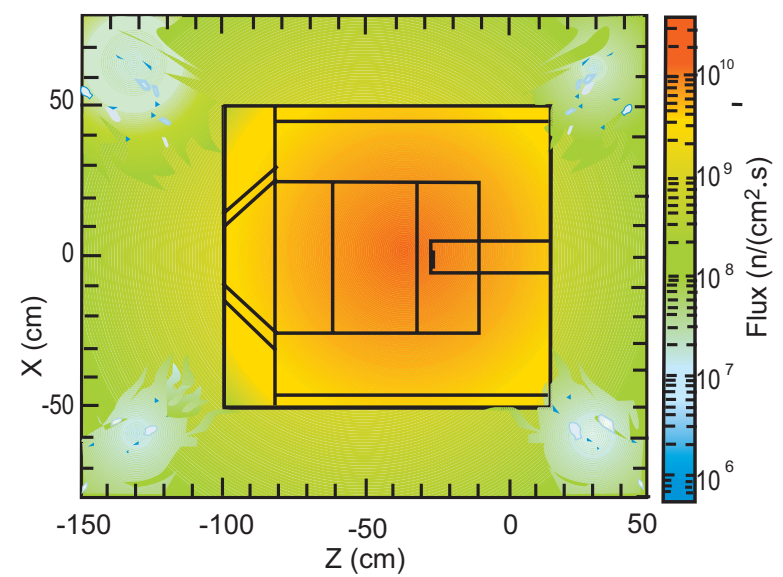

Fig. 2. Distribution of epithermal neutron flux in the DBSA.

of the moderator. The effectiveness of $\mathrm{Al}$ and $\mathrm{BiF}_{3}$ in producing epithermal neutron flux is due to $\mathrm{Al}$ that has high scattering cross section to energies of above 10 $\mathrm{keV}$ (Ivakhin et al., 2011). Interactions between neutrons and $\mathrm{Al}$ material produce epithermal neutrons through ${ }^{27} \mathrm{Al}(\mathrm{n}, 2 \mathrm{n}){ }^{27} \mathrm{Al}$ reactions (Ma et al., 2017). With regard to the contribution of $\mathrm{BiF}_{3}$ in moderating fast neutrons, it is because of the presence of fluorine $(\mathrm{F})$ in the $\mathrm{BiF}_{3}$ material. Fluorine is an element that has such high scattering cross section to fast neutrons that $\mathrm{BiF}_{3}$ material also contributes to increasing the number of epithermal neutrons and reducing the number of thermal neutrons. Lastly, Bi contributes to reducing gamma radiations (Fantidis and Nicolaou, 2018).

The quality of increasing epithermal neutrons is also sustained by the presence of the $\mathrm{FeC}$ filter placed in front of the moderator as a filter to high energy neutrons. The effectiveness of $\mathrm{FeC}$ as a high-energy neutron filter is attributed to the ability of $\mathrm{FeC}$ to in-elastically scatter high energy neutrons that pass through $\mathrm{FeC}$ material. Fe Material with $4 \mathrm{~cm}$ thickness is adequately effective in reducing the energy of the order of $\mathrm{MeV}$ into that of an epithermal neutron (Asnal et al., 2015). Figure 3 shows the spectrum of neutron flux produced by the DBSA calculated at the location of the aperture. The spectrum has a peak at the energy of $10 \mathrm{keV}$ with maximum epithermal neutron flux of $1.0 \times 10^{9} \mathrm{n} /\left(\mathrm{cm}^{2} . \mathrm{s}\right)$. Another researcher also found a similar value of epithermal neutron flux (Mitsumoto et al., 2010). Simulation results using the MCNPX code obtained the following characteristics of neutron beams: the epithermal flux of $1.0 \times 10^{9} \mathrm{n} /\left(\mathrm{cm}^{2} . \mathrm{s}\right)$, a ratio of epithermal to thermal and fast neutron of 344 and 85 , and a ratio

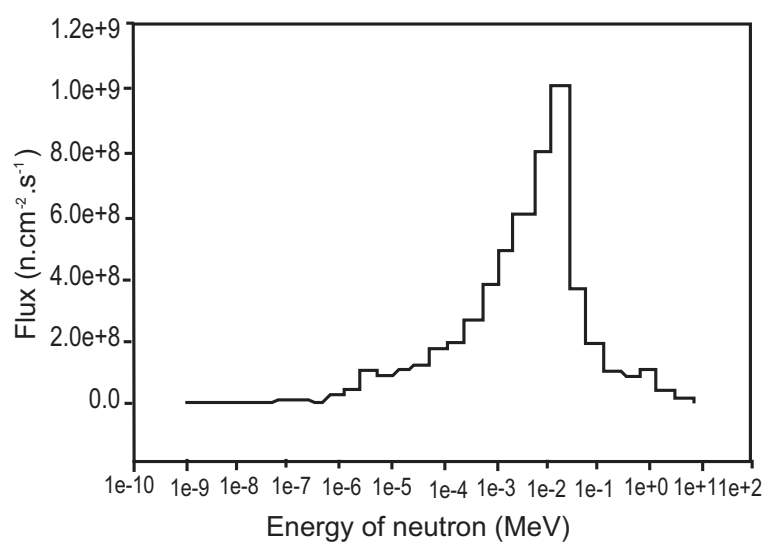

Fig. 3. Spectrum of the neutron flux at the end of DBSA.

of gamma-neutron dose to an epithermal neutron flux of $1.82 \times 10^{-13} \mathrm{~Gy} . \mathrm{cm}^{2}$.

Characteristics of neutron and gamma beams in water phantom. Fig. 4 shows the distribution of the epithermal neutron in the DBSA and the phantom. Epithermal neutrons that enter the phantom continually decrease in energy (depicted by changes in colour from yellow to blue in the phantom). The decrease in epithermal neutron flux is due to epithermal neutrons transforming into thermal neutrons during interactions with hydrogen atoms. This process is called thermalization (Hignett et al., 2002).

The neutron flux outside the DBSA, particularly outside the collimator decreases significantly. Based on the evaluation at $35 \mathrm{~cm}$ outside of the aperture, the neutron

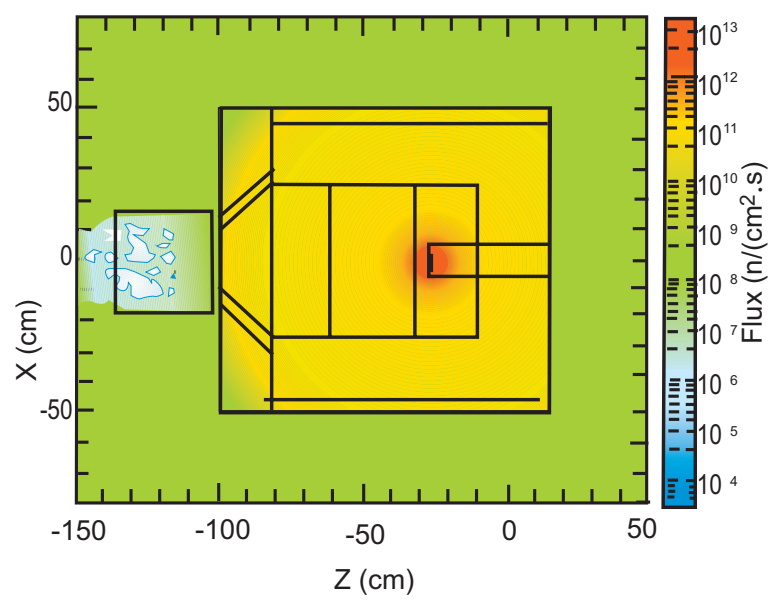

Fig. 4. Distribution of epithermal neutron flux in DBSA and water phantom 
flux decreases from $1.0 \times 10^{9} \mathrm{n} /\left(\mathrm{cm}^{2} . \mathrm{s}\right)$ to $1.0 \times 10^{7}$ $\mathrm{n} / \mathrm{cm}^{2} \mathrm{~s}$. As for the neutron flux outside the phantom, it decreases $1.0 \times 10^{9} \mathrm{n} /\left(\mathrm{cm}^{2} . \mathrm{s}\right)$ to $1.0 \times 10^{5} \mathrm{n} /\left(\mathrm{cm}^{2} . \mathrm{s}\right)$.

Figure 5 shows the distribution of gamma particles in DBSA and phantom. The gamma flux around the beryllium target is $10^{12}$ gamma $/\left(\mathrm{cm}^{2} . \mathrm{s}\right)$. The gamma particles are dominantly produced from interactions of protons with beryllium target through ${ }_{4}^{9} \mathrm{Be}(p, \alpha){ }_{3}^{6} L i^{*}$ reactions. The ${ }_{3}^{6} L i *$ decays into ${ }_{3}^{6} L i *$ releasing $\gamma$ (gamma). A small fraction of gamma ${ }_{4}^{9} \mathrm{Be}$ rays is also generated by capture reactions through ${ }_{4}^{9} \mathrm{Be}\left(n, n^{\prime} \gamma\right){ }_{5}^{10} \mathrm{Be}$ reactions ${ }_{4}^{9} \mathrm{Be}$ and inelastic collision mechanisms in the form of ${ }_{4}^{9}\left(n, n^{\prime} \gamma\right){ }_{3}^{10} B e$ reaction (Hu et al., 2016). Gamma rays are also produced from the reaction of neutrons with aluminum through ${ }^{27} \mathrm{Al}(\mathrm{n}, \gamma)^{28} \mathrm{Al}$ reactions. (Ivakhin et al., 2011). Gamma rays enter the phantom and interact with $\mathrm{H}$ and $\mathrm{O}$, losing their energy through mechanisms of photoelectric effect, Compton scattering, and pair production (Lamarsh and Baratta, 2001). These interactions cause gamma-ray flux to continually decline in the phantom. However, the gamma flux coming out from the DBSA is still quite high and hence a shielding is need to reduce the radiation. The increase gamma in the end of collimator could be caused by gamma radiation from the interaction of $\mathrm{Cd}$ and neutron.

Thermal neutron flux in water phantom. Figure 6 shows thermal neutron flux in the water phantom. The neutron thermal flux is distributed homogeneously throughout the volume of phantom. From the calculation using the MCNPX code the statistical uncertainty is found to be less than $5 \%$. Such a value indicates the accuracy in calculations. A calculation by the MCNPX

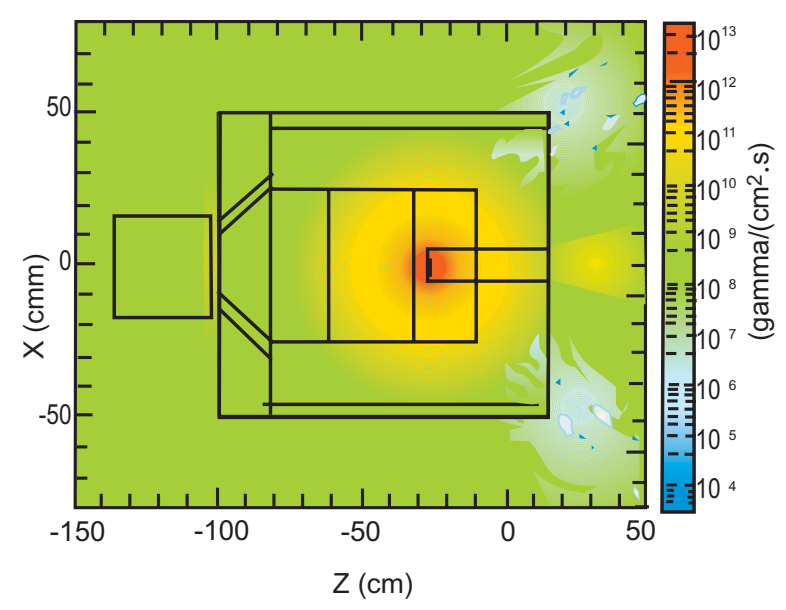

Fig. 5. Distribution of gamma in DBSA and water phantom.

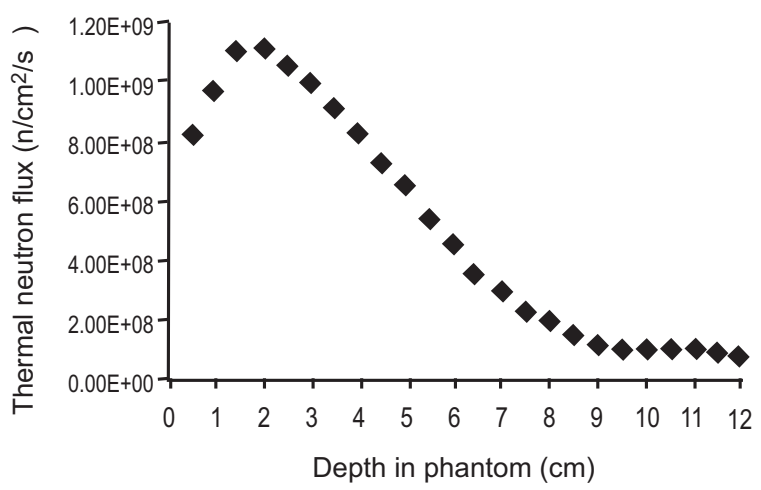

Fig. 6. Thermal neutron flux in the water phantom. The phantom is irradiated with epithermal neutrons from DBSA source.

is considered accurate when the statistical uncertainty is less than $10 \%$ (Pelowitz, 2005).

The maximum value of thermal neutron flux is $1.1 \times$ $10^{9} \mathrm{n} /\left(\mathrm{cm}^{2} . \mathrm{s}\right)$, obtained at $2 \mathrm{~cm}$ deep from the surface of the phantom. Other researches also obtained a similar result (Morcos and Naguib, 2012; Tanaka et al., 2011). The further deep epithermal neutron penetrate the phantom, the more increase in thermalization, causing the value of neutron flux to diminish. The value of thermal neutron flux at a depth of 5 and $12 \mathrm{~cm}$, reaches $60 \%$ and $20 \%$ of its maximum value, respectively. The decrease in neutron flux is caused by the thermalization of neutrons with H (Shaaban and Albarhoum, 2015). Based on the result, the thermal neutrons has an effective range in phantom at $8 \mathrm{~cm}$ depth.

Based on the characteristic of neutron flux produced by the DBSA source and the behavior of neutrons in the phantom, the neutron beams produced by the DBSA can be considered as the main neutron source for BNCT. The intensity of epithermal neutron flux is $1.0 \times 10^{9}$ $\mathrm{n} /\left(\mathrm{cm}^{2} . \mathrm{s}\right)$, which can be used as the source of a 1-hour cancer therapy for maximum dose of $50 \mathrm{~Gy}$ (Capoulat et al., 2014). The ability of thermal neutrons in a phantom shows that the neutron beams from the DBSA can be utilized as a neutron source for therapies of cancer situated at 2-8 cm. Some of the types of cancers that can be treated using the neutron source are head and neck cancer, glioblastoma, lung cancer, breast cancer, pancreas, brain tumor and sarcoma (Moss, 2014).

\section{Conclusion}

A Double-layer Beam Shaping Assembly (DBSA) is designed to produce epithermal neutrons for BNCT 
purposes. The spectrum of neutron beams calculated at the location of the aperture has the following characteristics: the epithermal neutron flux of $1.0 \times 10^{9}$ $\mathrm{n} /\left(\mathrm{cm}^{2} . \mathrm{s}\right)$, the ratio of epithermal to the thermal and fast neutron flux of 344 and 85 , repectively and the ratio of gamma-neutron dose to the epithermal neutron flux of $1.82 \times 10^{-13}$ Gy. $\mathrm{cm}^{2}$. This simulation study showed that epithermal neutron flux can penetrate up to $12 \mathrm{~cm}$ depth with the maximum flux of $1.1 \times 10^{9} \mathrm{n} /\left(\mathrm{cm}^{2} . \mathrm{s}\right)$ at $2 \mathrm{~cm}$ depth. The flux of neutron at $5 \mathrm{~cm}$ depth is found to be $60 \%$. The characteristics of neutron beams produced by the DBSA shows that they are adequate as the neutron source for BNCT, particularly for therapies of deeplylocated cancers. However, the DBSA still produces gamma fluxes, in which a proper shielding to reduce the gamma flux is needed for safety in BNCT therapies.

\section{Acknowledgement}

We thank the Ministry of Research, Technology and Higher Education for its BPPDN Scholarships and the BATAN for its consent to use the MCNPX and PHITS code, which allow this research to be conducted. We also thank late Prof. Dr. Kusminarto for his support in conducting research.

Conflict of Interest. The authors declare no conflict of interest

\section{References}

Adib, M., Habib, N., Bashter, I. I., El-Mesiry, M. S., Mansy, M. S. 2016. Simulation study of accelerator based quasi-mono-energetic epithermal neutron beams for BNCT. Applied Radiation and Isotopes, 107: 98-102.

Asnal, M., Liamsuwan, T., Onjun, T. 2015. An evaluation on the design of beam shaping assembly based on the D-T reaction for BNCT. Journal of Physics: Conference Series, 611: 1-7.

Avagyan, R., Avetisyan, R., Ivanyan, V., Kerobyan, I. 2017. Geant4 simulations of a beam shaping assembly design and optimization for thermal/ epithermal neutrons. Acta Physica Polonica B, 48: 1693-1699.

Capoulat, M. E., Minsky, D. M., Kreiner, A. J. 2014. Computational assessment of deep-seated tumor treatment capability of the ${ }^{9} \mathrm{Be}(\mathrm{d}, \mathrm{n}){ }^{10} \mathrm{~B}$ reaction for accelerator-based Boron Neutron Capture Therapy (AB-BNCT). Physica Medica, 30: 133-146.

Dao-wen, C., Jing-bin, L., Dong, Y., Hui-dong, W.,
Ke-yan, M. 2012. Improvement of the moderator's thermalization efficiency for $14 \mathrm{MeV}$ neutrons in boron neutron capture therapy. Journal of Radioanalytical and Nuclear Chemistry, 292: 1085-1088.

Fantidis, G.J., Nicolaou, G. 2018. Optimization of beam shaping assembly design for boron neutron capture therapy based on a transportable proton accelerator. Alexandria Engineering Journal, 57: 2333-2342.

Ghal-Eh, N., Goudarzia, H., Rahmani, F. 2017. FLUKA simulation studies on in phantom dosimetric parameters of a LINAC-based BNCT. Radiation Physics and Chemistry, 141: 36-40.

Hashimoto, Y., Hiraga, F., Kiyanagi, Y. 2015. Optimal moderator materials at various proton energies considering photon doserate after irradiation for an accelerator-driven ${ }^{9} \mathrm{Be}(\mathrm{p}, \mathrm{n})$ boron neutron capture therapy neutron source. Applied Radiation and Isotopes, 106: 88-91.

Hashimoto, Y., Hiraga, F., Kiyanagi, Y. 2014. Effects of proton energy on optimal moderator system and neutron-induced radioactivity of compact accelerator-driven ${ }^{9} \mathrm{Be}(\mathrm{p}, \mathrm{n})$ neutron sources for BNCT. Physics Procedia, 60: 332-340.

Hignett, C., Evett, S. R., Dane, J. H., Topp, G. C. 2002. Neutron thermalization. Methods of soil analysis, Part 4: 501-521.

Hu, G., Hu, H.S., Wang, S., Pan, Z.H., Jia, Q. G., Yan, M. F. 2016. The "neutron channel design"-A method for gaining the desired neutrons. AIP Advances, 6: 125025.

IAEA-TECDOC-1223: 2001. Current Status of Neutron Capture Therapy. International Atomic Energy Agency, Vienna, Austria.

Ivakhin, V.S., Tikhomirov, G.V., Bolozdynya, A.I., Efremenko, Y.V., Akimov, D.Y., Stekhanov, V.N., Akimov, A.G., Stekhanov, N. V. 2011. Modeling of Filters for Formation of Mono-Energetic Neutron Beams in the Research Reactor IRT MEPhI. Proceedings of GLOBAL, Makuhari, Japan, Paper No. 392341, December 11-16.

Kasesaz, Y., Khalafi, H., Rahmani, F. 2014. Design of an epithermal neutron beam for BNCT in thermal column of Tehran research reactor. Annals of Nuclear Energy, 68: 234-238.

Kasesaz, Y., Khala, H., Rahmani, F. 2013. Optimization of the beam shaping assembly in the D-D neutron generators- based BNCT using the response matrix method. Applied Radiation and Isotopes, 82: 55-59.

Khorshidi, A. 2017. Accelerator driven neutron source design via beryllium target and $208 \mathrm{~Pb}$ moderator 
for boron neutron capture therapy in alternative treatment strategy by Monte Carlo method. Journal of Cancer Research and Therapeutic, 13: 456-465.

Kreiner, J. A., Bergueiroa, J., Cartelli, D., Baldo, M., Castell, W., Asoia, J.G. 2016. Present status of Accelerator-Based BNCT, Reports of Practical Oncology and Radiotherapy, 21: 95-101.

Lai, B.L., Sheu, R.J. 2017. Shielding analyses of an AB-BNCT facility using Monte Carlo simulations and simplified methods, EPJ Web of Conferences, 153: 07023 .

Lamarsh, R.J., Baratta, J.B. 2001. Introduction to Nuclear Engineering, 761 pp., $3^{\text {rd }}$ edition, PrenticeHall, New Jersey, USA.

Ma, C.W., Lv,C. J., Zhang, G.Q., Wang, H.W., Zuo, J.X. 2017. Neutron-induced reactions on AlF3 studied using the optical model. Nuclear Instruments and Methods in Physics Research B, 356-357: 42-45.

Mitsumoto, T., Fujita, K., Ogasawara, T., Tsutsui, H., Yajima, S., Maruhashi, A. 2010. BNCT System Using $30 \mathrm{Mev} \mathrm{H}$ - Cyclotron, Proceedings of Cyclotron, Lanzhou, China, pp. 430-432.

Monshizadeh, M., Kasesaz, Y., Khalafi, H., Hamidi, S. 2015. MCNP design of thermal and epithermal neutron beam for BNCT at the Isfahan MNSR. Progress in Nuclear Energy, 83: 427-432.

Morcos, H. N., Naguib, K. 2012. A computer package for quasi-mono-energetic neutron filters. Annals of Nuclear Energy, 40: 237-240.

Moss, R. L. 2014. Critical review, with an optimistic outlook, on Boron Neutron Capture Therapy (BNCT). Applied Radiation and Isotopes, 88: 2-11.

Mozhayev, A. V., Piper, R. K., Rathbone, B. A., McDonald, J. C. 2016. Moderator design studies for a new neutron reference source based on the D-T fusion reaction. Radiation Physics and Chemistry, 123: 87-96.

Osawa, Y., Imoto, S., Kusaka, S., Sato, F., Tanoshita, M., Murata, I. 2017. Development of An Epithermal Neutron Field for Fundamental Researches for BNCT with A DT Neutron Source. European Physical Journal Web of Conferences, 153: 04008.

Pelowitz, D. B. 2005. MCNPXTM user's manual. Los Alamos National Laboratory, Los Alamos (https://www.mcnp.ir/admin/imgs/1354176297.2 .6.0_Users_Manual.pdf)

Raaijmakers, C.P.J., Nottelman, E.L., Mijnheer, B.J.
2000. Phantom materials for boron neutron capture therapy. Physics in Medicine and Biology, 45: 2353-2361.

Sato, T., Niita, K., Matsuda, N., Hashimoto, S., Iwamoto, Y., Noda, S. 2013. Particle and heavy ion transport code System, PHITS, version 2.52. Journal of Nucluclear Science Technology, 50: 913-923.

Sauerwein, G.A.W., Wittig, A., Moss, R., Nakagawa, Y. (eds ). 2012. Neutron capture therapy, Principles and Applications. 554 pp., Springer, New York, USA.

Shaaban, I., Albarhoum, M. 2015. Design calculation of an epithermal neutronic beam for BNCT at the Syrian MNSR using the MCNP4C code. Progress in Nuclear Energy, 78: 297-302.

Solovyev, A.N., Fedorov, V.V., Kharlov, V.I., Stepanova, U.A. 2015. Comparative analysis of MCNPX and GEANT4 codes for fast-neutron radiation treatment planning. Nuclear Energy and Technology, 1: 14-19.

Takata, T., Tanaka, H., Sakurai, Y., Maruhashi, A. 2010. Increase in irradiation beam intensity by using a hybrid target system in cyclotron-based neutron capture therapy. Journal of Nuclear Science and Technology, 47: 575-581.

Tanaka, H., Sakurai, Y., Suzuki, M., Masunaga, S., Matsumoto, T., Fujita, K. Kashino, G., Kinashi, Y., Liu, Y., Takada, M., Ono, K., Maruhashi, A. 2011. Experimental verification of beam characteristics for cyclotron-based epithermal neutron source (CBENS). Applied Radiation and Isotopes, 69: 1642-1645.

Tsukamoto, T., Tanaka, H., Yoshinaga, H., Mitsumoto, T., Maruhashi, A., Ono, K. 2011. A phantom experiment for the evaluation of whole body exposure during BNCT using cyclotron-based epithermal neutron source (C-BENS). Applied Radiation and Isotopes, 69: 1830-1833.

Türkmen, M., Ergün, S., Çolak, U. 2017. A new method in beam shaping: Multi-Objective Genetic Algorithm method coupled with a Monte-Carlo based reactor physics code. Progress in Nuclear Energy, 99:165-176.

Zaidi, L., Kashaeva, E.A., Lezhnin, S.I., Malyshkin, G.N., 2017. Neutron-Beam-Shaping Assembly for Boron Neutron-Capture Therapy. Physics of Atomic Nuclei, 80: 60-66. 